Although PMLA claims to be "receptive to [. . .] all scholarly methods and theoretical perspectives," it excludes to a large extent what Wright calls "literary analysis," which may still be of overwhelming interest to an overwhelming number of readers. This exclusivity may not derive from deliberate policy but could be due to the adventitious factor of the selection of the consultant readers and of the Advisory Committee. I wonder how these are appointed and whether care is taken to ensure that various areas and approaches are fairly represented, as far as possible. Couldn't PMLA solicit members at large to suggest names for consultant readers and Advisory Committee members, which could then be screened by the journal? A cumbersome process, but in view of the journal's status as an icon of literary studies, any step taken to reduce inadvertent cronyism and to achieve greater reader interest would be worthwhile.

The problem is not that PMLA is hospitable to new approaches — which it needs to be-but that it seems to have become increasingly inaccessible to other kinds of scholarship and criticism. Can it be that high-quality manuscripts are being submitted only in these new areas? If manuscripts not embodying certain methods or approaches are consistently turned down, that could surely discourage many from submission.

Finally, members may also be chary of publishing in PMLA because of the possibility of their being made targets of comments sometimes bordering on the ferocious. Louisa Mackenzie (117 [2002]: 13032) and Sherry Lutz Zivley (117 [2002]: 132) make this point. Since PMLA urges its members to be sensitive to the "social implications of language," will the journal allow insensitivity of other kinds in matters of language and style? And publish, therefore, especially in the Forum, comments that are not only intemperate but at times downright vituperative?

Let me conclude by reiterating the suggestions I have implicitly made. First, it may be worthwhile for PMLA to survey to what extent members read the articles. If it turns out, as I suspect it might, that the percentage of articles read is unusually low compared with other journals, steps should be taken to make PMLA more responsive to the needs and expectations of a large majority of its members instead of becoming captive to an articulate and highly visible minority. Second, while appointing consultant readers and Advisory Committee members, PMLA should solicit suggestions from members at large. Third, the editor and the copyeditors should ensure that unseemly language is not allowed to appear in the pages of the journal, even if-especially if-it emanates from big names in the profession.

$$
\begin{array}{r}
\text { R. K. Gupta } \\
\text { Indian Institute of Technology, Kanpur }
\end{array}
$$

\section{Montaigne and Scholarly Prose}

\section{TO THE EDITOR:}

George Hoffmann's Montaigne essay in the March issue of PMLA ("Anatomy of the Mass: Montaigne's 'Cannibals'” [117 (2002): 207-21]) is a model of poised, "old-fashioned" criticism. It avoids the jargon favored by some younger critics and instead gives us a close reading in historical context. Most essays in PMLA used to be like Hoffmann's, and one hopes that you will print more like it. I compliment the PMLA editors and Hoffmann.

My work was in medieval English, and though I am not a specialist in Montaigne or in French literature I found the essay informative, civilized, and delightfully written.

Thomas W. Ross Colorado College

Reply:

Praise that is both warm and unqualified is a rare thing. I appreciate Thomas W. Ross's generosity, but I feel more hopeful than he about the benefit of combining the best of the new with the old. Constraints in time make it easy to understand the attraction held by expeditious approaches to literature. But the current intellectual climate also offers an unparalleled freedom to pick from a wide array of methods and disciplines. Theory as well as literary history, theology as well as social history have enriched my understanding of Montaigne; literary studies would not have tolerated such eclecticism thirty years ago.

Call me an optimist, but I also believe that a brighter future awaits academic prose. Thankfully, clear style is not the exclusive purview of any critical school, and I take heart in the fact that so many of my colleagues at Michigan, hailing from a broad 